\title{
I solated classic Kaposi Sarcoma in an old female patient
}

\author{
Nursel Dilek ${ }^{1}$, Aziz Ramazan Dilek ${ }^{2}$, Yunus Saral ${ }^{1}$, Recep Bedir ${ }^{3}$ \\ 1. Dermatology Department of Recep Tayyip Erdoğan University Medical Faculty Hospital, Rize, Turkey. 2. Microbiology \\ Department of Recep Tayyip Erdoğan University, Medical Faculty Hospital, Rize, Turkey. 3. Pathology Department of \\ Recep Tayyip Erdoğan University Medical Faculty Hospital, Rize, Turkey.
}

Correspondence: Nursel Dilek. Address: Dermatology Department of Recep Tayyip Erdoğan University Medical Faculty Hospital, Rize, Turkey, 53000. Email: nur.dilek@hotmail.com

Received: December 19, 2013

Accepted: February 13, 2014

Online Published: February 28, 2014

DOI : $10.5430 /$ jst.v4n2p14

URL: http://dx.doi.org/10.5430/jst.v4n2p14

\section{Abstract}

Kaposi sarcoma (KS) is an angio-proliferative disorder and classified in terms of four clearly differentiated variants. Classic variant is an uncommon disease that it has an overwhelming male predominance and majority of cases patients are positive for HIV infections. We present HIV-negative female patient presenting multiple nodules on palmar and dorsal aspect of right wrist. Considering the male predominance of classic KS and positivity of HIV infections in majority of KS cases the patient presented to contribute to the literature.

\section{Key Words}

Kaposi sarcoma, Neoplasm, HIV

\section{I ntroduction}

Kaposi sarcoma (KS) is an angio-proliferative disorder characterized by proliferation of spindle-shaped cells, neoangiogenesis, inflammation, edema and enlarging cutaneous nodules and similar internal neoplasms, especially of the larynx, trachea, stomach, liver and colon are frequently observed findings ${ }^{[1,2]}$. KS is classified in terms of four clearly differentiated variants: classic, endemic, AIDS-related and iatrogenic ${ }^{[3]}$. Classic KS is an uncommon disease that it has an overwhelming male predominance, with a male-to-female ratio of approximately 10:1 to $15: 1^{[2]}$. Although human herpesvirus 8 (HHV-8) encodes oncogenic genes that could potentially induce all KS-related malignant phenotypes, HHV-8 infection in the general population rarely leads to KS. Existence of cofactors, such as HIV or drug-induced immunosuppression, that are required for the virus to induce a tumor ${ }^{[4]}$. In majority of cases patients are positive for HIV infections ${ }^{[5]}$. In the present case, patient was female, HIV negative and has classic KS with multiple nodules.

\section{Case report}

A 83-year-old female presented with a 10-month history of slow growing violaceous nodular lesions on palmar and dorsal aspect of right wrist which were $0.5-1.5 \mathrm{~cm}$ in diameter and non-tender. Systemic and general examination of the patient was unremarkable. Laboratory tests revealed that the patient was seropositive for human herpesvirus type 8 (HHV-8) and 
seronegative for human immunodeficiency virus (Western blot and ELISA). Excisional biopsy was obtained and submitted for histopathological examination. Microscopic examination showed a tumor which pleomorphic appearance composed of spindle cells, proliferating vascular structures and high Ki-67 proliferation index located in the dermis (Figure 1 and 2). On the basis of above findings, a diagnosis of KS was made. Radiotherapy suggested to the patient but the patient did not accept the radiotherapy. The patient is well till now, 6 months after initial diagnosis without any further intervention.

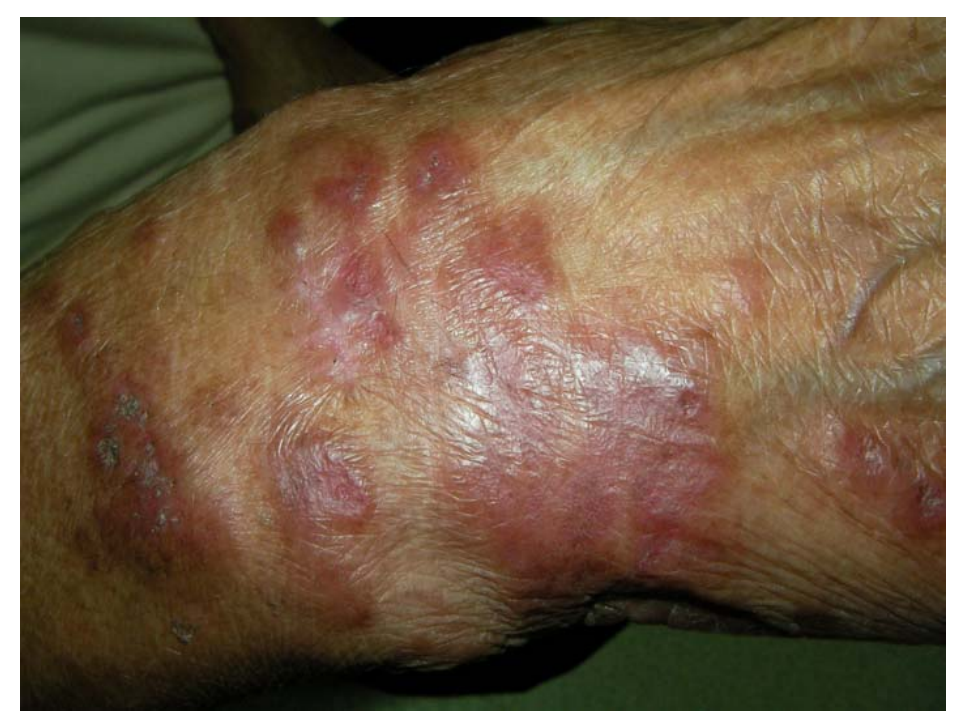

Figure 1. Dermal nodules on dorsal aspect of right wrist

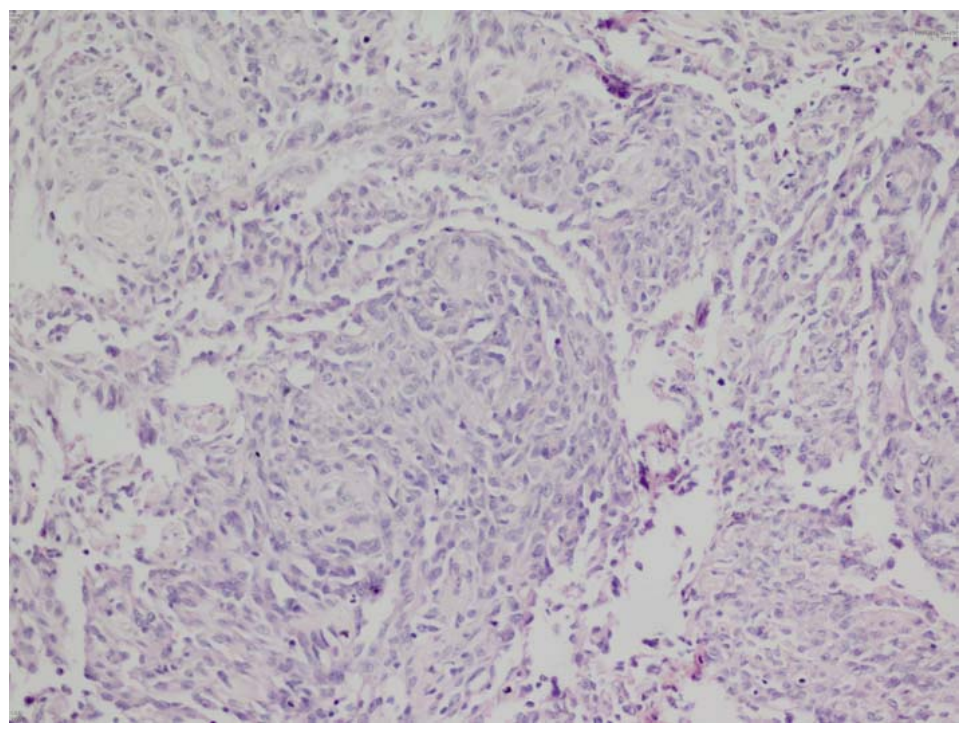

Figure 2. Section showing tumor composed of spindle cells X100

\section{Discussion}

Kaposi sarcoma is a lymphoangioproliferative disease often caused by KS associated herpesvirus, also known as human herpesvirus $8^{[6]}$. Although different variants according to the clinical patterns and epidemiological characteristics, the fact that histology findings are similar would suggest a common etiology ${ }^{[3]}$. The classical variant of Kaposi sarcoma occurs primarily as an indolent form in elderly people of mediterranean origin and affects mainly men ${ }^{[7]}$. As in our patient, 
HHV-8 has been linked closely with all types of KS but worldwide HHV-8 seropositivity has been found to exceed the incidence of KS. Therefore, investigators have justifiably implicated other cofactors ${ }^{[2,6]}$. Studies showed that the vast majority of spindle cells found in the later nodular stage of KS, express a latent profile of KSHV gene expression, where only a fraction of the total KSHV genes is expressed. Many more KSHV genes are expressed in lytically infected cells, which constitute $1 \%-5 \%$ of the total infected cells in KS lesions ${ }^{[8]}$. Although it is believed that KSHV only very rarely leads to the development of classic KS in immunocompetent individuals ${ }^{[9]}$. However a factor other than age which affects immunity was not found in our patient in examination.

Clinically, virtually all pigmented skin lesions are part of the differential diagnosis of KS and nowadays there has been an increasing in number of reported clinical and/or histologic variants of $\mathrm{KS}^{[10,11]}$. In a study a relatively high discordance rate was found between the clinical and the biopsy-proven diagnosis of $\mathrm{KS}^{[10]}$. Failure to identify a given lesion as $\mathrm{KS}$ could lead to delayed diagnosis or inappropriate management ${ }^{[1]}$.

Due to the KS heterogeneity, there are no standard therapeutic guidelines. The best therapeutic results are obtained in the classic KS with only local treatment ${ }^{[12,13]}$. Treatment of HIV-associated KS requires anti-retroviral therapy, which leads to both immune reconstitution and control of HIV viremia ${ }^{[14]}$. Radiotherapy is effective and often represents the best local treatment for palliation of pain, bleeding or edema, with response and complete remission rates of more than $90 \%$ and $70 \%$, respectively ${ }^{[12]}$. Based on the patient's clinical and laboratory findings, radiotherapy suggested to the patient but the patient did not accept the radiotherapy.

Considering the male predominance of classic KS $(90 \%)$, positivity of HIV infections in majority of Kaposi sarcoma cases, number and rarity of nodule placement of the patient we present HIV-negative female patient presenting multiple nodules to contribute to the literature.

\section{References}

[1] Ramírez-Amador V, Anaya-Saavedra G, Martínez-Mata G. Kaposi's sarcoma of the head and neck: a review. Oral Oncol. 2010. 46 (3): p.135-45. http://dx.doi.org/10.1016/j.oraloncology.2009.12.006

[2] Schwartz RA, Micali G, Nasca MR, Scuderi L. Kaposi sarcoma: a continuing conundrum. J Am Acad Dermatol. 2008. 59 (2): p.179-206. http://dx.doi.org/10.1016/j.jaad.2008.05.001

[3] González-Sixto B, Conde A, Mayo E, Pardavila R, de la Torre C, Cruces M. Kaposi sarcoma associated with systemic corticosteroid therapy. Actas Dermosifiliogr. 2007. 98 (8): p.553-5. http://dx.doi.org/10.1016/S0001-7310(07)70132-1

[4] Mesri EA, Cesarman E, Boshoff C. Kaposi's sarcoma and its associated herpesvirus. Nat Rev Cancer. 2010 Oct;10(10):707-19. http://dx.doi.org/10.1038/nrc2888

[5] Alam K, Maheshwari V, Varshney M, Aziz M, Shahid M, Basha M, Gaur K. Kaposi sarcoma presenting as dermal nodule.

[6] Kahl P, Buettner R, Friedrichs N, Merkelbach-Bruse S, Wenzel J, Carl Heukamp L. Kaposi's sarcoma of the gastrointestinal tract: report of two cases and review of the literature. Pathol Res Pract. 2007. 203 (4): p.227-31. http://dx.doi.org/10.1016/j.prp.2007.01.007

[7] Tanzi E, Zappa A, Caramaschi F, Amendola A, Lasagna D, Gatti L, Ascoli V, Rezza G, Zanetti AR. Human herpesvirus type 8 infection in an area of Northern Italy with high incidence of classical Kaposi's sarcoma. J Med Virol. 2005. 76 (4): p.571-5. http://dx.doi.org/10.1002/jmv.20400

[8] Direkze S, Laman H. Regulation of growth signalling and cell cycle by Kaposi's sarcoma-associated herpesvirus genes. Int J Exp Pathol. 2004. 85 (6): p.305-19. http://dx.doi.org/10.1111/j.0959-9673.2004.00407.x

[9] Schulz TF. The pleiotropic effects of Kaposi's sarcoma herpesvirus. J Pathol. 2006. 208 (2): p.187-98. http://dx.doi.org/10.1002/path.1904

[10] Van Bogaert LJ. Clinicopathological Proficiency in the Diagnosis of Kaposi's Sarcoma.

[11] Grayson W, Pantanowitz L. Histological variants of cutaneous Kaposi sarcoma. Diagn Pathol. 2008; 3: 31. http://dx.doi.org/10.1186/1746-1596-3-31

[12] Ruocco E, Ruocco V, Tornesello ML, Gambardella A, Wolf R, Buonaguro FM. Kaposi's sarcoma: etiology and pathogenesis, inducing factors, causal associations, and treatments: facts and controversies. Clin Dermatol. 2013; 31(4): p.413-22. 
[13] Martellotta F, Berretta M, Vaccher E, Schioppa O, Zanet E, Tirelli U. AIDS-related Kaposi's sarcoma: state of the art and therapeutic strategies. Curr HIV Res. 2009; 7(6): p634-8. http://dx.doi.org/10.2174/157016209789973619

[14] Uldrick TS, Whitby D. Update on KSHV epidemiology, Kaposi Sarcoma pathogenesis, and treatment of Kaposi Sarcoma. Cancer Lett. 2011. 305(2): p150-62. http://dx.doi.org/10.1016/j.canlet.2011.02.006 